\title{
A cross sectional study of the independent effect of occupation on lung function in British coal miners
}

\author{
Sarah Lewis, John Bennett, Kathie Richards, John Britton
}

\begin{abstract}
Background-Chronic bronchitis and emphysema are now recognised complications of occupational exposure to coal dust, and since 1992 compensation has been available for miners with impaired lung function provided that they also have $x$ ray film evidence of pneumoconiosis. However, many miners with heavy exposure to coal dust and impairment of lung function therefore do not qualify for compensation because they do not have simple pneumoconiosis. In the present study attempts were made to determine whether coal mining is an independent risk factor for impairment of lung function in a group of Nottinghamshire miners with no evidence of simple pneumoconiosis, by comparing these men with a group of local controls who were not occupationally exposed.
\end{abstract}

Method-Forced expiratory volume in one second $\left(F E V_{1}\right)$ and forced vital capacity (FVC) were obtained on 1286 miners with no evidence of pneumoconiosis on $x$ ray film. Lung function data were also obtained from a random sample of 567 men aged between 40 and 70 living in a district of Nottingham and who had never worked in the mining industry or in any other dusty occupation. Multiple linear regression in SPSS was used to estimate the mean independent effect of mining on $F E V_{1}$ and FVC after adjustment for age, height, and smoking, in all miners and controls, and in a subgroup of men of 45 and under. In men of 45 and under, the independent effects of mining and smoking on the probability of a deficit of one litre or more from modelled predicted FEV $_{1}$ values were computed with logistic regression in EGRET.

Results-There was a significant mean effect of mining on $\mathrm{FEV}_{1}$ after adjustment for age, height, and smoking of $-155 \mathrm{ml}$ (95\% confidence interval $(95 \%$ CI) -74 to $-236 \mathrm{ml}, P<0.001$ ), but the size of effect was inversely related to age such that in men of 45 and under the estimated mean effect of mining was $-251 \mathrm{ml}(95 \% \mathrm{CI}$ -140 to $-361 \mathrm{ml}, P<0.001)$. In this subgroup of younger men, $4 \cdot 7 \%$ of miners and $0.7 \%$ of controls had a deficit of one litre or more from predicted $\mathrm{FEV}_{1}$ values, and in logistic regression, there was a marginally significant independent effect of both smoking $(P=0.05)$ and mining $(P=0 \cdot 07)$ for a deficit of this magnitude.
Conclusions-Occupational exposure to coal dust is associated with a small mean deficit in lung function even in the absence of simple pneumoconiosis, and independently from the effects of smoking. The requirement that miners should have evidence of pneumoconiosis to qualify for compensation for impaired lung function is therefore unjustified.

(Occup Environ Med 1996;53:125-128)

Keywords: coal mining; lung function; simple pneumoconiosis

The effect of coal mining on lung function and the issue of compensation of coal miners for loss of lung function attributable to their occupation is a subject of persistent controversy. The deleterious effect of progressive massive fibrosis on pulmonary function is now widely accepted, ${ }^{1-3}$ but although many studies have shown that rates of loss of lung function in miners seem to be unrelated to the presence of simple pneumoconiosis, ${ }^{4-6}$ recent criteria for compensation to British coal miners specified the presence of simple pneumoconiosis as a prerequisite for compensation. ${ }^{7}$

To establish rational and fair criteria for the award of compensation to coal miners, it is therefore important to confirm that coal dust exposure causes impairment of lung function in miners without pneumoconiosis and to establish the mean and distribution of the size of the effect. Data available now derive predominantly from uncontrolled studies, or from studies which used controls within the industry, and suggest an average decrement in one second forced expiratory volume $\left(\mathrm{FEV}_{1}\right)$ of between 150 and $420 \mathrm{ml}$ associated with an average lifetime exposure to coal dust. ${ }^{488} \mathrm{It}$ has been suggested that large deficits in lung function in coal miners may be attributable less to coal dust than smoking, ${ }^{910}$ but although a deficit of one litre or more from predicted is a second prerequisite for compensation, to date the relative contribution of mining exposure and smoking to deficits of this magnitude is unclear. In this study we have therefore estimated the effect of coal mining on lung function and on the occurrence of large deficits in lung function by taking data from 1286 Nottinghamshire coal miners with no evidence of pneumoconiosis on $x$ ray film, and compared these with 567 local controls with no occupational history of coal mining or other occupational dust exposure. We have esti- 
mated the independent effect of coal mining with adjustment for smoking, and in a subset of these men who were lifetime non-smokers we examined the relative contribution of dust exposure and smoking to large deficits in lung function.

\section{Subjects and methods}

Occupational records were obtained from British Coal on all of 1436 miners employed in seven collieries in the East Midlands, in whom $\mathrm{FEV}_{1}$ and forced vital capacity (FVC) were measured and chest $x$ ray films were performed between March 1992 and June 1993 as part of a routine screening of lung health offered (by personal letter) to all miners over the age of 40 at these seven collieries. The records included details of age, measured height, self reported smoking status (lifetime non-smoker, current smoker, exsmoker) and mining work type at the time of lung testing (face worker, elsewhere underground, surface worker, and staff (supervisory)). Complete data were available on 1302 workers, with ages ranging from 40 to 66 . Of the 134 missing values, most were for height only. $x$ Ray films were performed and pneumoconiosis classified according to ILO recommendations (1980) with one reader only, and 11 miners with evidence from a chest $x$ ray film of simple pneumoconiosis and five miners with no $x$ ray film result were excluded from the present study. Of the remaining 1286, 942 were currently employed underground, 314 were surface workers, and 30 were supervisory staff.

Control lung function data were drawn from a sample of 850 men aged between 40 and 70 who were part of a larger random sample of 2644 adults from a local authority area of Nottingham who participated in a survey of diet and lung disease in 1991. The equipment and technique for lung function measurement was comparable with that used by British Coal, taken similarly as the best of three measurements on a vitalograph (Buckingham, UK) calibrated according to standard calibration procedures. More extensive details of these subjects have been presented elsewhere. ${ }^{11}$ Of these 850 men, information on current and previous lifetime occupations within the mining, textile, foundry, and quarry industries were obtained from 735 men who responded by questionnaire in 1993. Our control population comprised the 567 of these who had never worked in the mining industry, or had worked in the industry for less than 12 months but had never worked underground, and had never worked in a dusty atmosphere within the textile, foundry, or quarry industries. The age distribution of this group encompassed the age range of the miners, and was evenly distributed over this age range.

Multiple linear regression was performed in SPSS version $4 \cdot 1^{12}$ to investigate the size and independence of the effect of mining exposure on lung function, after adjustment for age, height, and smoking. The presence of interaction between factors was examined. To exclude potential residual confounding by smoking we repeated the analysis after excluding all smokers and exsmokers. Further similar multiple linear regression models were produced to examine the effect of including underground miners only.

As the transfer of miners from underground to surface jobs or to employment outside the mining industry is likely to be health related, the independent effect of mining on a subgroup of 595 miners and 147 controls aged 45 or less was investigated with the aim of reducing this potential healthy worker effect. The $\mathrm{FEV}_{1}$ and FVC values for these subjects were again regressed against age, height, smoking, and mining status.

The predicted values of $\mathrm{FEV}_{1}$ according to age and height were then computed for each miner up to the age of 45 with the multiple regression coefficients obtained from this final multiple linear regression model, and the absolute difference between observed and predicted $\mathrm{FEV}_{1}$ values was computed for each worker. The independent effects of coal mining and smoking in determining an absolute difference of one litre or more were examined with logistic regression in EGRET. ${ }^{13}$

\section{Results}

In a multiple regression model, with data on all miners and controls and with terms for age, height, smoking, and mining or control status, the coefficients for age gave an estimated mean (SEM) change in $\mathrm{FEV}_{1}$ of -45 (3) $\mathrm{ml} / \mathrm{y}$ and for height +38 (2) $\mathrm{ml} / \mathrm{cm}$ increase in height (table). The independent mean effect of current smoking was $-229 \mathrm{ml}$ (95\% confidence interval (95\% CI) -160 to -298$)$, and of past smoking $-162 \mathrm{ml}(95 \% \mathrm{CI}-69$ to -254). After adjustment for age, height, and smoking, the effect of mining on $\mathrm{FEV}_{1}$ was $-155 \mathrm{ml}(95 \% \mathrm{CI}-74$ to -236$)$. Restriction

Effects of age, height, smoking, and mining exposure on FEV $(\mathrm{ml})$

\begin{tabular}{llll}
\hline & $\begin{array}{l}\text { All men } \\
\text { Multiple regression } \\
\text { coefficients } \\
(95 \% \text { CI })\end{array}$ & $\begin{array}{l}\text { Men <45 } \\
\text { Multiple regression } \\
\text { coefficients } \\
(95 \% \text { CI })\end{array}$ & $\begin{array}{l}\text { Lifetime non-smokers } \\
\text { Multiple regression } \\
\text { coefficients } \\
(95 \% \text { CI })\end{array}$ \\
\hline $\begin{array}{l}\text { Intercept (age }=40, \\
\text { height }=170 \mathrm{~cm}, \\
\text { never smoker, } \\
\text { non-miner) }\end{array}$ & & & \\
$\begin{array}{l}\text { Age (/y increase) } \\
\text { Height }(/ \mathrm{cm} \text { increase) }\end{array}$ & $3719(3652$ to 3786$)$ & $3713(3627$ to 3799$)$ & $3843(3767$ to 3919$)$ \\
Current smoker & $-45(-39$ to -50$)$ & $-29(-7$ to -50$)$ & $-46(-40$ to -53$)$ \\
Exsmoker & $38(33$ to 42$)$ & $38(32$ to 44$)$ & $40(35$ to 46$)$ \\
Miner & $-229(-160$ to -298$)$ & $-285(-200$ to -370$)$ & $-128(-33$ to -220$)$ \\
\hline
\end{tabular}


FEV, by age, smoking, and mining status with height $=$ $170 \mathrm{~cm}$.
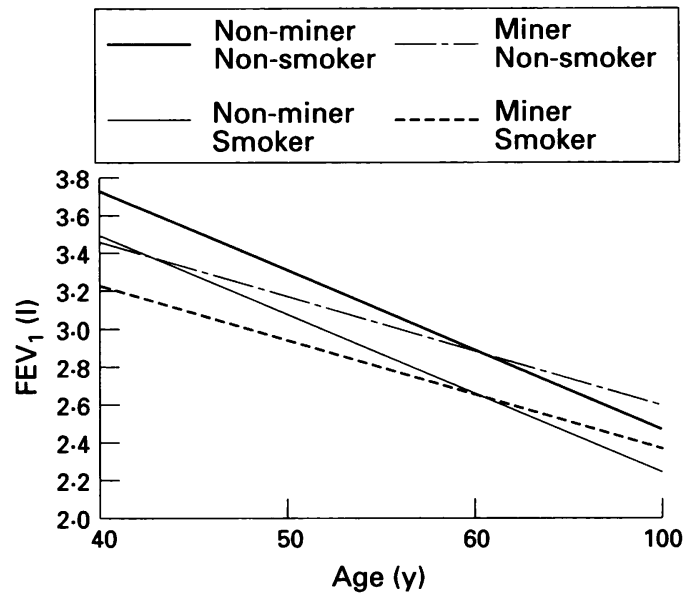

of this analysis to miners working underground resulted in a slightly lower estimate of the effect of mining on $\mathrm{FEV}_{1}$ which, after adjustment for age, height, and smoking, was $-139 \mathrm{ml}(95 \% \mathrm{CI}-53$ to -225$)$. However, in the analysis including all miners, there was a significant interaction term between mining exposure and age such that the effect of mining exposure decreased with increasing age. Thus at the age of 40 the mean effect of mining exposure on $\mathrm{FEV}_{1}$ was $-262 \mathrm{ml}(95 \% \mathrm{CI}$ -162 to -362 ), whereas at the age of 50 , the mean effect was $-128 \mathrm{ml}(95 \% \mathrm{CI}-58$ to -197 , figure). There was no significant interaction between age and smoking $(P=0.3)$, and after adjustment for an age by smoking interaction, the effect of mining on $\mathrm{FEV}_{1}$ was estimated as $-278 \mathrm{ml}$ and $-125 \mathrm{ml}$ at ages 40 and 50 respectively, and was thus little changed from the unadjusted values. There was also no significant interaction between smoking and miner or control status $(P=$ 0.4 ), although the coefficients implied a greater effect of both current and past smoking in miners.

A slightly greater proportion of the miners were reported to be current smokers $(38.3 \% v$ $24.5 \%$ respectively) and a smaller proportion were exsmokers than among the controls $(7.9 \% v 38.1 \%)$, but a greater proportion of miners were self reported never smokers $(53.8 \% v 37.4 \%$ in controls). In lifetime nonsmokers, multiple linear regression including all miners and controls showed that, after adjustment for the covariates age and height, there was a significant mean effect of mining on $\mathrm{FEV}_{1}$ of $-128 \mathrm{ml}(\mathrm{P}=0.007,95 \% \mathrm{CI}$ -33 to -220 ).

In a multiple linear regression of $\mathrm{FEV}_{1}$ on age, height, smoking, and miner or control status (restricted to miners and controls of 45 or less) the estimated independent effect of mining on $\mathrm{FEV}_{1}$ was $-251 \mathrm{ml}(95 \% \mathrm{CI}-140$ to $-361, P<0.001)$. The age and height coefficients from this model were used to compute a predicted $\mathrm{FEV}_{1}$ and an absolute difference between observed and predicted $\mathrm{FEV}_{1}$ for all men up to 45. A deficit of one litre or more from the predicted value occurred significantly more often in miners than controls $(4.7 \%$ and $0.7 \%$ respectively, $P=0.05$ ) and significantly more often in smokers and exsmokers than in non-smokers (current smokers $6 \cdot 5 \%$, exsmokers $4.1 \%$, non-smokers $2.8 \%, P=0.03$ ). Logistic regression to establish the relative effect of smoking and mining on the occurrence of a deficit of one litre or more was limited by low power, but there was a marginally significant independent effect of both smoking and mining (odds ratio (OR) for current $v$ never smoking $=2 \cdot 45,95 \%$ CI $1 \cdot 17$ to $5 \cdot 14$, $\mathrm{P}=0.05, \mathrm{OR}$ for mining $=6.54,95 \% \mathrm{CI}$ 0.86 to $49.56, P=0.07$ ).

After adjustment in multiple regression for age, height, and smoking, there was no significant effect of mining on FVC, whether all or just underground miners were included.

\section{Discussion}

A relation between increased exposure to respirable coal dust and lung function has been shown in both cross sectional and longitudinal studies, ${ }^{4-689}$ and in studies carried out both before and after legislation introduced during the 1970 s to reduce mean coal face dust concentrations. According to recent compensation legislation introduced in the United Kingdom, to establish grounds for compensation a British miner must have spent at least 20 years mining underground, have a deficit in $\mathrm{FEV}_{1}$ of at least one litre from the predicted value, and have $x$ ray film evidence of at least stage 1 pneumoconiosis. The rationale for inclusion of pneumoconiosis as a criterion for compensation, as well as the history of at least 20 years working underground, is far from clear. Most evidence from studies within mining populations suggests that the effect of coal dust exposure on $\mathrm{FEV}_{1}$ in miners without massive fibrosis is independent of the presence of simple pneumoconiosis, ${ }^{4-6}$ but the magnitude of the effect of mining in the absence of pneumoconiosis, and the relative effect of cigarette smoke and coal dust in causing large deficits in lung function, remain unclear.

The present study has compared lung function values in miners, many of whom will have entered the industry during the 1970 s, with local controls not occupationally exposed, and shown a significant effect of employment in the mining industry on $\mathrm{FEV}_{1}$, which was independent of age, height, and smoking, and which occurred in the absence of pneumoconiosis. There was no corresponding significant effect on FVC, consistent with obstructive airways disease. The size of the effect on $\mathrm{FEV}_{1}$, estimated at $155 \mathrm{ml}$, is of similar magnitude to that reported in previous studies of coal miners $^{45}$ and is also similar in magnitude to the estimated effect of smoking in this population. More importantly, the significant interaction between the effect of mining and age, such that the effect of mining reduced with age and the decreased magnitude of effect in those working underground, strongly suggests that those who are most sensitive to the effects of underground mining exposure are more likely to leave the industry, or to transfer to surface jobs within the industry, and so our estimates are likely to be substantial underestimates of the true mining effect. Our analysis of men 
under the age of 46 has shown an average effect of underground mining exposure of $-251 \mathrm{ml}$, and has also shown that there is considerable variation in this effect such that some men have a notable deficit from predicted lung function, which is partly attributable to underground mining exposure in both smokers and non-smokers, but is more likely to occur in miners who also smoke.

A considerable limitation of the present study is the lack of any details of measured individual exposure to respirable dust, or of cumulative lifetime exposure. An exposureresponse relation is generally considered a stronger indicator of causality, but studies which have measured cumulative exposure in miners have shown a small mean effect, particularly if miners who have left the industry have not been included. ${ }^{8}$ This, together with the strong healthy worker effect shown in the present study and elsewhere ${ }^{45}$ suggest that cumulative exposure may be less important in determining the extent of the effect on a worker than individual susceptibility to the effects of coal dust exposure. We also only have sufficient information to establish the number of pack-years smoked in controls, so that adjustment was made for smoking status only, and it is possible that our estimate of the effect of mining is affected by residual confounding by smoking. The effect of current smoking estimated at $229 \mathrm{ml}$ was of similar magnitude to the effect of 30 pack-years in the controls, and is consistent with that described in cross sectional studies elsewhere, ${ }^{14}$ and the effect of mining in men up to the age of 45, estimated at $251 \mathrm{ml}$, was greater than the estimated effect on $\mathrm{FEV}_{1}$ of the heaviest rate of smoking in controls in this age group, which was $182 \mathrm{ml}$ attributable to 40 pack-years. Most importantly, our data set was sufficiently large to show that there remained a significant, although slightly smaller, effect of coal mining in non-smokers, and we have no evidence to suggest that miners were more likely than controls to understate their smoking habits. Also, although comparison of miners with controls outside the industry enabled us to show the healthy worker effect and to reduce the magnitude of this effect in comparison with studies which have used controls from within the industry, it inevitably increased the potential for differential exposure to other determinants of lung function which may be acting as confounders in our estimate of the effect of mining on lung function. The inclusion of several controls who were slightly older than the oldest miner, however, had no effect on the estimated effect of mining (if controls $<67$ years only were included the estimated effect of mining on $\mathrm{FEV}_{1}$ was $158 \mathrm{ml}$ ). Our data were also subject to potential selection bias in that the 1302 miners were in fact self selected as $80 \%$ of those miners who were invited to attend for pulmonary function testing attended, and it is likely that those who did not attend were those with fewer respiratory symptoms, although to some extent the same may be true of the controls. That miners and controls were not excluded on the basis of specific respiratory conditions such as asthma, and that spirometric measurements were made standing and sitting in miners and controls respectively, are both potential sources of bias, likely to have reduced our estimate of the effect of mining on FEV

The results of this study, and in particular the strong healthy worker effect, suggest once again that a longitudinal controlled study which includes miners who have left the industry is necessary to establish the true magnitude and distribution of the effect of coal dust exposure. As such a study is currently an unlikely proposition given the current decline of the mining industry in the United Kingdom, grounds for compensation relating to employment in the mining industry must be based on the evidence available to date. This study provides further evidence of a small but clear effect of coal mining in the absence of pneumoconiosis which, given the bias introduced by healthy worker effects, is likely to be at least $250 \mathrm{ml}$ on average, and to be one litre in about $5 \%$ of cases. Although on an individual basis it is clearly not possible to establish the relative contribution of smoking and coal dust exposure to large deficits in lung function, our findings show that deficits of one litre or more related to mining exposure can occur independently of smoking. We have also shown that this effect of coal mining on lung function is present in miners with no evidence of pneumoconiosis. Our findings therefore suggest that the requirement that coalminers should have grade 1 pneumoconiosis to qualify for compensation in the United Kingdom should be revoked.

We thank Dr Douglas Scarisbrick, Principal Medical Officer, British Coal Corporation, for providing the data and for assistance in the preparation of the present paper, and British Coal for funding the analyses presented.

1 Lyons JP, Campbell H, Gough J. Emphysema in coal workers' pneumonconiosis. BMF 1970;481-7.

2 Lyons JP, Campbell $H$. Evolution of disability in coal workers' pneumoconiosis. Thorax 1976;31:527-33.

3 Lyons JP, Ryder RC, Seal RME, Wagner JC. Emphysema in smoking and non-smoking coal workers with pneumoconiosis. Bull Eur Physiopathol Respir 1981;17:75-85.

4 Soutar CA, Hurley JF. Relation between dust exposure and lung function in miners and ex-miners. $\mathrm{Br} f$ Ind Med 1986;43:307-20.

5 Marine WM, Gurr D, Jacobsen M. Clinically important respiratory effects of dust exposure and smoking in
British coal miners. Am Rev Respir Dis 1988;137:106-12.

6 Nemery B, Brasseur L, Veriter C, Frans A. Impairment of ventilatory function and pulmonary gas exchange in nonventilatory function and pulmonary gas exch
smoking coal miners. Lancet $1987 ; 1427-30$.

7 Chronic bronchitis and emphysema. Command paper 2091, November 1992. ISBN 0-10-120912-6.

8 Love RG, Miller BG. Longitudinal study of lung function in coal-miners. Thorax 1982;37:193-7.

9 Soutar C, Campbell S, Gurr D, Lloyd M, Love R, Cowie $\mathrm{H}$, et al. Important deficits of lung function in three modern colliery populations. Am Rev Respir Dis 1993;147: 797-803.

10 Oxman AD, Muir DCF, Shannon HS, Stock SR, Hnizdo E, Lange HJ. Occupational dust exposure and chronic $\mathrm{E}$, Lange Ho the evidence. Am Rev Respir Dis 1993;148:38-48

11 the evidence. Am Rev Respir Dis 1993;148:38-48 Lewis S, et al. Dietary magnesium, lung function, wheezing, and airway hyperreactivity in a random adult populaing, and airway hyperreactivity in a ran

12 Norusis MJ/SPSS Inc. SPSS/PC + 4. Base manual. Chicago. SPSS, 1990.

13 Statistics and Epidemiology Research Corporation. EGRET. Seattle: SERC, 1988

14 Xu X, Dockery DW, Ware JH, Speizer FE, Ferris BG. Effects of cigarette smoking on rate of loss of pulmonary function in adults: a longitudinal assessment. Am Rev Respir Dis 1992;146:1345-8. 